\title{
Growth and clinical course of children with Crohn's disease
}

\author{
Anne M Griffiths, Phuongbich Nguyen, Claire Smith, James H MacMillan, Philip M Sherman
}

\begin{abstract}
Growth impairment is a common complication of childhood Crohn's disease, but longitudinal data and follow up studies into adulthood are sparse. This study reviewed the records of 100 Tanner stages 1 and 2 children (66 males, 34 females) consecutively diagnosed with Crohn's disease at this hospital between January 1980 and June 1988. The influence of sex, anatomical location of disease, severity of symptoms, corticosteroids, and surgical intervention on growth were analysed by univariate and multivariate regression analysis. At diagnosis mean standard deviation score (SDS) for height was -1.11 (1.28) (males -1.14 (1.26) females $-1.05(1.33)$ ). Twenty one children were below the third centile for height. During years one and two height velocity $(\mathrm{cm} / \mathrm{y})$ was $4.4(2 \cdot 3)$ and $5 \cdot 1(2 \cdot 7)$, but $40 \%$ of children in year one and $33 \%$ of children in year two grew less than expected $(<4 \mathrm{~cm})$. Forty nine children grew $<4 \mathrm{~cm} / \mathrm{y}$ during two or more of the 4.9 (1.8) years of follow up. Severity of gastrointestinal symptoms was the major factor influencing linear growth velocity $(\mathbf{p}<0.01$ for years one and two). Despite the high prevalence of growth impairment, the subset of children who had reached maturity by the time of the study $(n=67)$ nevertheless maintained their height centile. The SDS for height at ultimate follow up was $-0.82(1 \cdot 1)$. Compared with diagnosis, change in SDS was +0.35 $(1 \cdot 08)$. Growth increments were comparable for surgically treated patients $v$ patients only treated medically and among patients stratified by location of disease. Females $(n=25)$ achieved greater catch up growth than males $(n=42)$. Ultimate SDS for height for females was $-0.48(0.91) v-1.02(1.19)$ for males. Change in SDS for height was $+0.66(1.27)$ for females $v+0.16(0.90)$ for males $(p=0.02)$. These data confirm the frequency of growth impairment in childhood Crohn's disease. After diagnosis, however, the prognosis for ultimate linear growth is good. (Gut 1993; 34: 939-943)
\end{abstract}

TABLE I Severity of gastrointestinal symptoms during individual years

\begin{tabular}{|c|c|c|c|}
\hline Severity & Definition & $\begin{array}{l}\text { Year } 1 \\
(n=100)\end{array}$ & $\begin{array}{l}\text { Year } 2 \\
(n=99 \star)\end{array}$ \\
\hline Quiescent & $\begin{array}{l}\text { No gastrointestinal or extraintestinal symptoms reported; } \\
\text { normal complete blood count and erythrocyte } \\
\text { sedimentation rate }\end{array}$ & 14 & 23 \\
\hline Mild & Some symptoms but not needing prednisone treatment & 54 & 42 \\
\hline Moderate & $\begin{array}{l}\text { Intermittent symptomatic exacerbations warranting } \\
\text { prednisone or nutritional treatment }\end{array}$ & 23 & 25 \\
\hline Severe & $\begin{array}{l}\text { Chronic unremitting symptoms warranting prednisone or } \\
\text { alternate treatment }\end{array}$ & 9 & 9 \\
\hline
\end{tabular}

$\star$ One patient was lost to follow up during year two (very well during that year) but returned and completed follow up to ma
Childhood Crohn's disease is often complicated by retardation of linear growth and pubertal development. ${ }^{2}$ Few long term studies, however, specifically consider the epidemiology and natural history of impairment of growth in an at risk population. ${ }^{34}$ Incomplete measurement of growth indices has often prevented or biased retrospective assessment of such data. ${ }^{5}$ The data base for inflammatory bowel diseases established in our hospital has allowed us to review our experience. We evaluated children with Crohn's disease presenting before or during early puberty and analysed the variation in their subsequent linear growth in relation to anatomical distribution of disease, severity of gastrointestinal symptoms, sex, and therapeutic interventions.

\section{Methods}

The records of 100 consecutive children diagnosed as having Crohn's disease at the Hospital for Sick Children between January 1980 and June 1988 were reviewed. Only patients at Tanner stage 1 or 2 of pubertal development when initially assessed were included in this study. In the Metropolitan Toronto area neither general paediatricians nor adult gastroenterologists independently manage such young patients and no paediatric gastroenterologist practises at another institution. This restriction ensured that the study population was representative of the range of paediatric Crohn's disease rather than a select group requiring tertiary care.

All patients were followed up for a minimum of two years through the inflammatory bowel diseases clinic. Patients transferred after initial diagnosis elsewhere and patients referred for consultation only were excluded. Gastrointestinal symptoms (abdominal pain, diarrhoea, anorexia) as well as extraintestinal manifestations were registered on standardised forms. Complete blood count and erythrocyte sedimentation rate were regularly measured at clinic visits. Heights were routinely measured on a wall mounted stadiometer. Radiology of the small intestine and either double contrast barium enema or colonoscopy were used to determine the anatomical distribution of disease.

During each of the first two years after diagnosis, gastrointestinal symptoms recorded on standardised forms were classified as quiescent, mild, moderate, or severe as defined in Table I. For all 100 patients, the influence of anatomical localisation of disease, sex, severity of gastrointestinal symptoms, duration of daily prednisone use, and of nutritional intervention on the height velocities during each of the first two years were analysed by multiple regression analysis. Stepwise model selection was used. The 
coefficient of determination ( $\mathbf{R}^{2}$ (adjusted)) was used to measure the proportion of variation explained by individual factors. Before multiple regression analysis, univariate tests were used to assess the independent effect of each factor on height velocity. $t$ Tests were used for two level factors; ANOVA was employed for factors with several levels, and simple linear regression for continuous variables.

The outcome of patients who had completed their linear growth (defined by attainment of Tanner stage 5 pubertal development and less than $1 \mathrm{~cm}$ of growth in 12 months) at the time of the study was also reviewed. Standard deviation scores (SDS) for height at diagnosis and at ultimate follow up were calculated according to the equation ${ }^{6}$ :

$$
\mathrm{SDS}=\frac{\chi-\bar{\chi}}{\mathrm{S} \bar{\chi}}
$$

where $\chi$ is the observed height, $\bar{\chi}$ the mean height for the given age and sex, and $S \bar{\chi}$ the standard deviation of the mean. The program CASP was used for this purpose. ${ }^{7}$ The $\bar{\chi}$ and $S \bar{\chi}$ for a given age and sex were obtained from the data of the National Center for Health Statistics. ${ }^{8}$ Univariate tests and multiple regression analysis were used to assess the influence of anatomic localisation of disease, sex, overall gastrointestinal symptom severity (as defined in Table II), and surgical intervention on the change in SDS for height over the total period of follow up.

Results are expressed as mean (SD). Univariate and multiple regression analysis was by SAS and Proc REG' was used for all regression analysis. All computations were on a DEC System 5000 computer running Ultrix Version $4 \cdot 1$, Research Computing, The Hospital for Sick Children.

\section{Results}

\section{INITIAL PRESENTATION}

Between January 1980 and June 1988100 children ( 66 boys, 34 girls) at Tanner stage 1 $(n=76)$ or Tanner stage $2(n=24)$ of pubertal development were diagnosed at the Hospital for Sick Children to have Crohn's disease. The mean age at diagnosis was $11 \cdot 3(2 \cdot 3)$ (range 5.4-16.6) years. Disease was localised to the terminal ileum alone or plus caecum in 41 patients, ileum plus colon in 36 , more proximal ileum or jejunum in 14 , and the colon alone in nine children. The mean duration of symptoms before diagnosis was $9 \cdot 1(11 \cdot 4)$ months.

The mean standard deviation score (SDS) for height at diagnosis was $-1 \cdot 11(1 \cdot 28)$, and was similar for both males $(-1 \cdot 14(1 \cdot 26))$ and females $(-1.05(1 \cdot 33))$. Poor growth was cited as a presenting symptom for 31 of the 100 children. The height of 21 patients was less than the third centile according to the charts of Tanner and Whitehouse $^{10}$ (SDS for height $<-1 \cdot 8$ ). Bone age ${ }^{11}$ was delayed by more than two standard deviations for chronological age in 21 of the 27 patients for whom it was determined.

FIRST AND SECOND YEARS AFTER DIAGNOSIS

Eighty five of the children were treated with prednisone during the first year $(1 \mathrm{mg} / \mathrm{kg} /$ day for six weeks then tapering to discontinue over one to two months). Table I summarises their subsequent clinical course. After initial treatment 14 patients had no further gastrointestinal symptoms and normal complete blood count and erythrocyte sedimentation rate for the remainder of that year (quiescent disease). Fifty four children had intermittent or continuing mild symptoms not requiring further prednisone during the first year. Twenty three children had more severe but intermittent symptoms and nine had chronically severe disease throughout the year. Twenty six children received at least two courses of daily prednisone in the regimen described. Alternate day treatment was used in 11 patients for one to five months. Nutritional treatment was used in eight patients (seven elemental diet, one total parenteral nutrition) for two to four months during the first year.

The range of severity of gastrointestinal symptoms was similar during the second year of follow up; 23 patients had quiescent disease, 42 children mild symptoms, 25 moderate, and nine severe (Table I). Prednisone was used less during the second year; twenty six patients received one course and 10 children two or more courses. Eight patients received alternate day treatment for periods varying between two and 12 months. Twelve patients were treated with nasogastric tube feeding of an elemental diet for intervals of two to 12 months and one with central line parenteral nutrition for eight months. Eight children were started on immunosuppressant drugs (azathioprine or 6-mercaptopurine) during the first two years after diagnosis. Twelve patients underwent intestinal resection during the first two years of follow up.

The mean height increment during the first year after diagnosis was $4 \cdot 4(2 \cdot 3) \mathrm{cm}$. Forty children failed to achieve a normal prepubertal growth velocity of $4 \mathrm{~cm}$ per year. ${ }^{10}$ During the second year, the mean height velocity was $5 \cdot 1$ $(2 \cdot 7) \mathrm{cm}$. Thirty three children grew less than $4 \cdot 0 \mathrm{~cm}$.

Severity of gastrointestinal symptoms was the major factor influencing linear growth during the first two years. Height velocity decreased with increasing gastrointestinal symptoms $(p<0.01$, $\mathrm{R}^{2}=0.16$ during year one and $\mathrm{p}<0.01, \mathrm{R}^{2}=0.20$ during year two). The Figure shows the mean height velocity during each year according to severity of gastrointestinal symptoms. The duration (in months) of daily prednisone treatment adversely affected height velocity in year two when analysed independently by simple linear regression $(p=0.01)$. After adjusting for severity of symptoms, however, duration of corticosteroid administration was not a significant predictor of height velocity. No differences in mean linear growth velocities were found between males and females or among patients stratified by anatomical localisation of disease. As exemplified by the year two data shown in Table III, fewer patients with ileal and caecal inflammation or ileal inflammation alone grew at a subnormal velocity. Yearly height increments did not vary consistently with duration of nutritional treatment. 
Height velocity (mean (SD) $\mathrm{cm} / \mathrm{y}$ ) according to severity of gastrointestinal symptoms $(p<0.01) ;(A)$ year one; $(B$ year two. Numbers of patients are shown for each category.
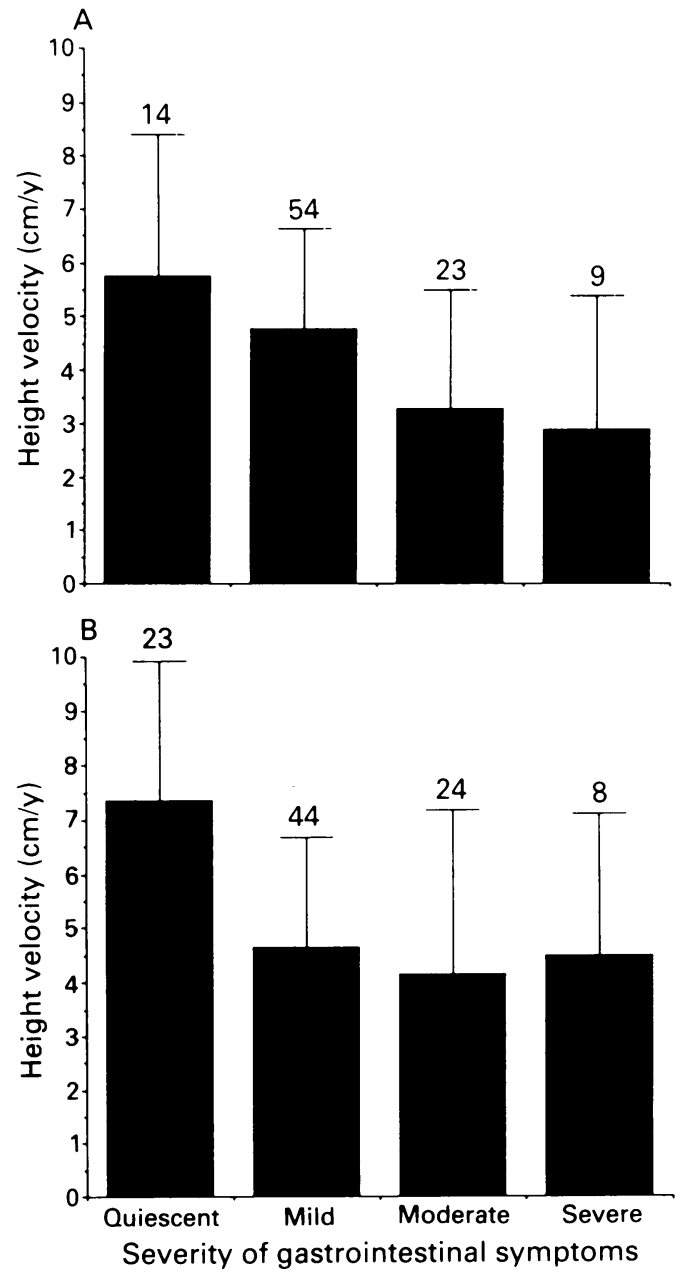

TABLE V Variation in growth according to sex among children followed up to maturity

\begin{tabular}{lllll}
\hline Sex & No & $\begin{array}{l}\text { Initial height } \\
\text { SDS }\end{array}$ & $\begin{array}{l}\text { Ultimate height } \\
\text { SDS }\end{array}$ & $\begin{array}{l}\text { Changes in } \\
\text { height SDS }\end{array}$ \\
\hline Female & 25 & $-1.01(1.06)$ & $-0 \cdot 48(0 \cdot 91)$ & $0 \cdot 66(1 \cdot 27)^{\star}$ \\
Male & 42 & $-1.22(1.30)$ & $-1.02(1.19)$ & $0 \cdot 16(0.90)^{\star}$
\end{tabular}

${ }^{\star} \mathrm{p}=0 \cdot 02$, partial $\mathrm{R}^{2}=0 \cdot 07$

TABLE VI Variation in growth with surgical intervention among children followed up to maturity

\begin{tabular}{lllll}
\hline Resection & No & $\begin{array}{l}\text { Initial height } \\
\text { SDS }\end{array}$ & $\begin{array}{l}\text { Ultimate height } \\
\text { SDS }\end{array}$ & $\begin{array}{l}\text { Changes in } \\
\text { height SDS }\end{array}$ \\
\hline Yes & 18 & $-1.48(1.05)$ & $-0.95(0.81)$ & $0.45(0.91)^{\star}$ \\
No & 49 & $-1.01(1.25)$ & $-0.77(1.20)$ & $0.31(1.33)^{\star}$ \\
\hline${ }^{\star} \mathrm{p}=0.52$. & & & & \\
\end{tabular}

LONG TERM COURSE

The 100 children were followed up for $4.9(1 \cdot 8)$ years (minimum two years) to a mean age of $16 \cdot 1$ $(2 \cdot 2)$ years. Table II summarises the spectrum of severity of their gastrointestinal symptoms. After initial treatment the overall clinical course was characterised by only mild gastrointestinal symptoms in 33 children. In 18 children a period of severe disease resolved or improved (usually after surgical intervention) to similarly mild or quiescent disease for the duration of follow up. Thirty two children experienced repeated severe exacerbations but also clear cut remissions. Symptoms were chronically severe and unremitting in 17 patients. Nineteen patients were treated with immunosuppressant drugs (6mercaptopurine or azathioprine). Thirty five children received a period of nutritional treatment (four total parenteral nutrition, 31 nasogastric tube feeding). Intestinal resection was performed in 36 patients during the period of follow up. Forty nine children grew less than 4 $\mathrm{cm}$ per year during at least two years of follow up. Bone age was delayed by more than two standard deviations in 42 of the 60 patients for whom it was determined.

A subset of 67 children (42 males, 25 females) had reached maturity (defined by Tanner stage 5 and less than $1 \mathrm{~cm}$ of height increment during the preceding year) by the time of this study. Their mean age at follow up was 17.6 (0.9) years for males and $17 \cdot 0(1 \cdot 1)$ years for females. Ultimate SDS for height of this subgroup was -0.82 $(1 \cdot 11)$ compared with $-1 \cdot 14(1 \cdot 21)$ at diagnosis. The change in SDS during follow up was +0.35 (1.08). Despite the high frequency of growth impairment as a complication of paediatric Crohn's disease, 45 of the 67 patients had maintained or increased their SDS for height during a follow up interval of $5 \cdot 4(1 \cdot 7)$ years.

Tables III to VI give the variation in ultimate height with individual factors. The change in SDS for height during follow up varied according to the overall severity of gastrointestinal symptoms as defined in Table II ( $p=0 \cdot 03$, partial $\mathrm{R}^{2}=0 \cdot 10$ ) and according to sex. Females showed greater height gain with a change in SDS score of $+0.66(1.27)$ compared with $+0.16(0.90)$ for males $\left(p=0 \cdot 02\right.$, partial $\left.R^{2}=0 \cdot 07\right)$. The ultimate SDS for height of females was $-0.48(0.91)$ and for males $-1 \cdot 02(1 \cdot 19)$. Eighteen of the group of 67 children underwent resection before compleamong children followed up to maturity

\begin{tabular}{|c|c|c|c|c|}
\hline Overall symptom severity & No & $\begin{array}{l}\text { Initial height } \\
\text { SDS }\end{array}$ & $\begin{array}{l}\text { Ultimate height } \\
\text { SDS }\end{array}$ & $\begin{array}{l}\text { Changes in } \\
\text { height SDS }\end{array}$ \\
\hline Mild & 26 & $-0 \cdot 88(1 \cdot 40)$ & $-0 \cdot 43(1 \cdot 05)$ & $0.58(1 \cdot 2$ \\
\hline Moderate & 15 & $-1 \cdot 17(1 \cdot 09)$ & $-1 \cdot 15(1 \cdot 16)$ & $0.03(0.73$ \\
\hline Moderate or severe with sustained remission & 14 & $-1 \cdot 48(1.07)$ & $-0 \cdot 70(1 \cdot 11)$ & $0 \cdot 68(0 \cdot 90$ \\
\hline Chronically severe & 12 & $-1 \cdot 12(1 \cdot 09)$ & $-1.37(0.97)$ & $-0.11(0.96$ \\
\hline
\end{tabular}

${ }^{\star} p=0 \cdot 03$, partial $R^{2}=0 \cdot 10$, association of overall severity of gastrointestinal symptoms with increment in SDS for height during follow up. 
tion of growth. Their SDS for height increased by $0.45(0.91)$. The 49 children not treated surgically increased their SDS score for height a similar amount $(0.31(1.33) ; \mathrm{p}=0.52)$. Table III shows that increments in SDS for height were comparable among patients stratified by disease location $(p=0 \cdot 25)$. Children with isolated jejunal, or proximal ileal inflammation, or both were disadvantaged, however, by their short stature at diagnosis. Six of 10 with only such small bowel involvement were below the third centile for height when their disease was recognised. Of all patients followed up to maturity 17 were below the third centile for height at diagnosis (SDS for height $-2 \cdot 81(0 \cdot 57))$. Although their linear growth improved (change in SDS for height $=+0.87(0.93), 10$ of the 17 had final heights below the third centile (SDS for ultimate height $=-1.94(0.93))$.

\section{Discussion}

This study presents data on both the initial presentation and the long term clinical course of childhood Crohn's disease. The 100 consecutive patients were all Tanner stage 1 or 2 at the time of diagnosis. This restriction was applied primarily so that the frequency of growth impairment and its natural history could be determined in an at risk population. Furthermore, referral patterns in Metropolitan Toronto and surrounding areas are such that young teenagers and children are almost invariably sent to inflammatory bowel diseases clinic at the Hospital for Sick Children for confirmation of diagnosis, treatment, and follow up care. The patient sample therefore resembles that of a population based study.

Our data, as summarised in Tables I and II, emphasise the variability of severity of illness encountered among young patients as recognised previously among adults with Crohn's disease. ${ }^{12} 13$ One third of the children experienced no more than mild symptoms after initial treatment and were not subsequently treated with corticosteroids during the follow up period. The classic pattern of exacerbations of disease activity of sufficient severity to warrant corticosteroid treatment interspersed with convincing remissions was found in 32 patients. Another 18 experienced a dramatic improvement as their previously severe disease entered a sustained quiescent phase most often after intestinal resection (14 patients), but sometimes coincident with use of immunosuppressive medications (two patients), bowel rest (one patient), or both (one patient). Seventeen children failed to achieve remission but had chronic intestinal symptoms despite treatment throughout their course. Such variability in clinical course dictates that treatment of childhood Crohn's disease be tailored to the individual patient.

The potential complication of impairment of growth in Crohn's disease is unique to paediatric patients. Its reported frequency depends very much on definition. ${ }^{2}$ Impaired height velocity is the most sensitive index. Kanof $e t a l^{14}$ reported a decrease in height velocity in $88 \%$ of Tanner 1 or 2 patients at the time of diagnosis and before treatment. Our data show that despite treatment nearly one half $(49 \%)$ of 100 such children grew less than $4 \mathrm{~cm}$ per year during at least two individual years of follow up. Bone age, although determined in only 60 patients, was delayed by more than two standard deviations in $\mathbf{4 2}$ of these.

Severity of gastrointestinal symptoms had the most pronounced influence on linear growth velocity during each of the first two years of follow up. As would be expected months of daily prednisone treatment also adversely affected growth. ${ }^{15}$ Alternate day prednisone was not often used, even though such treatment has been recommended by some gastroenterologists as routine maintenance treatment of Crohn's disease. ${ }^{16}$ The beneficial effect of this practice on activity of disease and linear growth has not been subjected to confirmation in a controlled trial. The variability in the clinical course of paediatric inflammatory bowel disease as described in this study makes us reluctant to advise a regimen such as alternate day corticosteroids from the time of diagnosis. One third of the patients had only mild symptoms after the initial treatment of their disease. The role of alternate day corticosteroids among children who experience chronic or frequently relapsing symptoms, however, deserves further study.

Only eight and 12 children respectively received nutritional treatment for varying intervals during years one and two. Such infrequent use prohibits any conclusion about the outcome of these patients compared with the others. Furthermore, nutritional treatment tended to be recommended for the more symptomatic and already growth impaired children. Several prospective studies have shown improvement in linear growth in individual children with nutritional restitution. ${ }^{17}{ }^{18} \mathrm{~A}$ randomised prospective multicentre study is currently evaluating the effect of intermittent elemental diet administration $v$ alternate day prednisone on the long term cinical course and growth of children with Crohn's disease. ${ }^{19}$ The efficacy of elemental diet treatment in controlling disease activity ${ }^{2021}$ makes it an important potential alternative to traditional corticosteroid treatment, particularly for children.

Despite the frequency of growth impairment during the course of childhood Crohn's disease, the 67 children followed up until completion of linear growth ultimately maintained their height centile (SDS for final height of $-0.82(1 \cdot 11) v$ SDS for height at diagnosis of $-1 \cdot 14(1 \cdot 21)$ ). Because height centiles before illness were not often available, however, the impact of inflammatory bowel disease on their genetically determined growth potential cannot be completely assessed. Overall severity of gastrointestinal symptoms influenced the final height centile as it had height velocity during the initial years of follow up. The poorer prognosis for linear growth among boys who develop Crohn's disease before puberty has not been previously reported. Ultimate standard deviation score for height was $-0.48(0.91)$ for females and $-0.02(1.19)$ for males despite comparable height centiles at diagnosis. As the severity of Crohn's disease and linear growth velocity during the first two years of follow up among males and females were comparable, it is possible that varying demands on growth during normal puberty may account 
for these differences. Males grow more during normal puberty than do females. ${ }^{22}$ In the presence of chronic illness, the nutritional requirements for the greater and more sustained normal growth spurt are less likely to be met. ${ }^{23}$ It may be particularly important, therefore, to aggressively target nutritional treatment at boys with Crohn's disease, by using long term nocturnal nasogastric $^{17}{ }^{18}$ or gastrostomy tube feeding.

The role of surgery as a means of improving growth in childhood Crohn's disease is controversial. ${ }^{42-27}$ Castille $e t \mathrm{al}^{4}$ reported greater ultimate height in a surgically treated cohort of children compared with those managed medically. We recently reported out experience with intestinal resection. ${ }^{27}$ Height velocity in the first year after operation increased dramatically compared with the year before operation among patients with growth potential. As a follow up to these findings we analysed the effect of intestinal resection before completion of growth on ultimate height. The net change in height centile compared with diagnosis was comparable for surgically and non-surgically treated patients followed up to completion of their growth. Neverthless, a beneficial effect of surgery on ultimate height is suggested, particularly given the more severe disease of the surgically treated group.

The children who were below the third centile for height at diagnosis (SDS for height $<-1 \cdot 8$ ) are of particular concern. Although with treatment they made gains in growth at least comparable with other patients, $59 \%$ ( 10 of 17 ) followed up to maturity failed to reach the third centile for adult height. Special consideration of alternative strategies, such as nutritional or surgical intervention, is warranted for children who are already stunted at the time of diagnosis and therefore need extra catch up growth. ${ }^{23}$ The importance of early recognition of Crohn's disease before it has such an adverse impact on linear growth is highlighted. The 67 children who had reached maturity at the time of this study tended to have been diagnosed earlier in the decade than those still growing. The predominance of patients below the third centile in this earlier cohort ( 17 of 21 ) suggests that indeed more prompt identification of Crohn's disease now occurs.

P Nguyen was the recipient of a Medical Research Council of Canada Studentship Award. P Sherman is the recipient of a Career Scientist Award from the Ontario Ministry of Health.

1 Burbige EJ, Huang S-S, Bayless TM. Clinical manifestations of Crohn's disease in children and adolescents. Pediatrics 1975; 55: 866-71.
2 Kirschner BS. Growth and development in chronic inflammatory bowel disease. Acta Paediatr Scand (Suppl) 1990; 366: 98-104

3 Puntis J, NcNeish AS, Allan RN. Long-term prognosis of Crohn's disease with onset in childhood and adolescence. Gut 1984; 25: 329-36.

4 Castile RG, Telander RL, Cooney DM, Ilstrup DR, Perrault J, van Heerden J, Stickler GB. Crohn's disease in children: assessment of the progression of disease, growth and prognosis. F Pediatr Surg 1980; 15: 462-69.

5 Barton JR, Ferguson A. Failure to record variables of growth and development in children with inflammatory bowel disease. BMF 1989; 298: 865-6.

6 Dietz WH, Hartung R. Changes in height velocity of obese preadolescents during weight reduction. Am $\mathcal{f}$ Dis Child 1985; 139: 705-7.

7 Centers for Disease Control. The CDC anthropometric software package version 3.0. Atlanta, Georgia: The Centers for Disease Control, Center for Health Promotion and Education, 1987.

8 Hamill PVV, Drizd TA, Johnson CL, Reed RB, Roche AF. NCHS growth curves for children birth -18 years. Department of Health, Education and Welfare (United States Series 11 number 165, DHEW Pub No (PHS) 78-1650). Washington DC: 1978.

9 The Reg Procedure. Chapter 36, 1351-1456. In: SAS/STAT User's Guide, Version 6, fourth Ed, Vol 2, Cary NC: SAS Institute, 1989.

10 Tanner JM, Davies PW. Clinical and longitudinal standards for height and height velocity for North American Children. 7 Pediatr 1985; 107: 317-29.

11 Greulich WW, Pyle SL. Radiographic atlas of skeletal development of the hand and wrist. Stanford: Stanford University Press, 1950.

12 Farmer RG, Hawk WA, Turnbull RB Jr. Clinical patterns in Crohn's disease: a statistical study of 615 cases. Gastroenterology 1975; 68: 627-35.

13 Meyers S, Janowitz HD. Natural history of Crohn's disease. An analytic review of the placebo lesson. Gastroenterology 1984; 87: 1189-92.

14 Kanof ME, Lake AM, Bayless TM. Decreased height velocity in children and adolescents before the diagnosis of Crohn's disease. Gastroenterology 1988; 95: 1523-7.

15 Elders JM, Wingfield BS, McNatt MI, Clarke JS, Hughes ER. Glucocorticoid therapy in children. Effect on somatomedin Glucocorticoid therapy in children. Effect on
secretion. Am $\mathcal{F}$ Dis Child 1975; 129: $1393-6$.

16 Whittington PF, Barnes HV, Bayless TM. Medical management of Crohn's disease in adolescence. Gastroenterology 1977; 72: 1338-44.

17 Belli DC, Seidman E, Bouthillier L, Weber AM, Roy CC, Pletincx $M$ et al. Chronic intermittent elemental diet improves growth failure in children with Crohn's disease. Gastroenterology 1988; 94: 63-10.

18 Aiges H, Markowitz J, Rosa J, Daum F. Home nocturnal supplemental nasogastric feedings in growth-retarded adolescents with Crohn's disease. Gastroenterology 1989; 97: 905-10.

19 Seidman E, Bagnell P, Griffiths AM, Issenman R, Jones A Canadian Collaborative Crohn's Disease Study. GastroCanadian Collaborative C
enterology 1991; 100: A249.

20 O'Morain C, Segal AW, Levi AJ. Elemental diet as primary treatment of acute Crohn's disease: a controlled trial. $B M \mathcal{F}$ 1984; 288: 1859-62.

21 Sanderson IR, Udeen S, Davies PS et al. Remission induced by an elemental diet in small bowel Crohn's disease. Arch Dis Child 1987; 62: 123-7.

22 Tanner JM, Whitehouse RH, Takaishi M. Standards from birth to maturity for height, weight height velocity and weight velocity. British Children, 1965 Part I. II. Arch Dis Child 1966; 41: 454-71; 613-35.

23 Forbes GB. A note on the mathematics of 'catch-up' growth. Pediatr Res 1974; 8: 929-31.

24 Homer DR, Grand RJ, Colodny AH. Growth, course and prognosis after surgery for Crohn's disease in children and prognosis after surgery for Crohn's dise
adolescents. Pediatrics 1977; 59: 717-25.

25 McLain BI, Davidson PM, Stokes KB, Beasley SW. Growth after gut resection for Crohn's disease. Arch Dis Child 1990; 65: $760-2$.

26 Lipson AB, Savage MO, Davies PSW. Acceleration of linear growth following intestinal resection for Crohn's disease. Eur F Pediatr 1990; 149: 687-90.

27 Griffiths AM, Wesson DE, Shandling B, Corey M, Sherman P. Factors influencing postoperative recurrence of Crohn's disease in childhood. Gut 1991; 32: 491-5. 